\title{
Multiwalled carbon nanotubes induce altered morphology and loss of barrier function in human bronchial epithelium at noncytotoxic doses
}

This article was published in the following Dove Press journal:

International Journal of Nanomedicine

25 August 2014

Number of times this article has been viewed

\section{Ryan J Snyder \\ Salik Hussain \\ Annette B Rice \\ Stavros Garantziotis}

Clinical Research Unit, National Institute of Environmental Health Sciences/National Institutes of Health, Research Triangle Park, NC, USA
Correspondence: Ryan J Snyder Clinical Research Unit, National Institute of Environmental Health Sciences, III TW Alexander Drive, Mail Drop CRU-17I Research Triangle Park, Durham, NC 27709, USA

$\mathrm{Tel}+\mathrm{I} 9193164836$

Fax +19195419854

Email snyder3@niehs.nih.gov
Abstract: Multiwalled carbon nanotubes (MWCNTs) have seen increasing application in consumer products over the past decade, resulting in an increasing risk of human exposure. While numerous toxicological studies have been performed using acute high doses of various carbonaceous nanomaterials, the effects of longer-term, low doses of MWCNTs remain relatively unexplored. This study examined bronchoscopy-derived healthy human bronchial epithelial cells exposed in submerged culture to noncytotoxic doses of MWCNTs over 7 days. Under these conditions, doses as low as $3 \mu \mathrm{g} / \mathrm{mL}$ caused altered cell morphology, superficially resembling fibroblasts. Electrical impedance of the epithelial monolayer was greatly reduced following MWCNT exposure. However, Western blot and polymerase chain reaction showed no elevated expression of the fibroblast markers, vimentin, $\alpha$-smooth muscle actin, or fibronectin, indicating that a mechanism other than epithelial-mesenchymal transition may be responsible for the changes. Phalloidin and tubulin immunostaining showed disruption of the cytoskeleton, and confocal imaging showed a reduction of the tight junction proteins, zona occludens 1 and occludin. We propose that MWCNTs interfere with the cytoskeleton of the lung epithelium, which can result in a harmful reduction in barrier function over time, even at noncytotoxic doses.

Keywords: multiwalled carbon nanotubes, bronchial epithelium, transepithelial electrical resistance, cytoskeleton, morphology, human

\section{Introduction}

In recent years, engineered nanoparticles have seen application in an increasing number of consumer products and industrial applications. Since 2005, the number of consumer products utilizing engineered nanoparticles has more than quadrupled. ${ }^{1}$ Carbon nanotubes (CNTs), a common engineered nanomaterial, have been used in a variety of applications, including construction materials, stain-free clothing, and electronics, ${ }^{2}$ with further potential applications in drug delivery, ${ }^{3}$ cancer therapy, ${ }^{4}$ and as semiconductors. ${ }^{5}$ For these reasons, it is becoming increasingly important to determine the potential health effects of environmental and occupational exposure to these CNTs.

Of the numerous varieties of CNTs, multiwalled carbon nanotubes (MWCNTs) are thought to have the greatest potential health risks, due to their reduced flexibility and similarity in shape to asbestos fibers. ${ }^{6}$ Previous studies have demonstrated the ability of MWCNTs to induce pulmonary inflammation, fibrosis, formation of granuloma, and airway injury ${ }^{7-9}$ when delivered by instillation or inhalation. ${ }^{10}$ There is also evidence of oxidative stress ${ }^{11}$ and apoptosis ${ }^{12}$ in bronchial epithelial airway cells exposed to CNTs in vitro. However, while acute in vitro exposure of human lung cells to high 
doses $(12-200 \mu \mathrm{g} / \mathrm{mL})$ of MWCNTs has been previously studied, ${ }^{13-15}$ the subcytotoxic effects of lower doses over time periods longer than 48 hours remain relatively unexplored. Additionally, many in vitro studies ${ }^{12,16}$ of the toxicity of MWCNTs have investigated their effects on subconfluent cultures in an exponential growth phase, when they are more susceptible to environmental stressors. Comparatively little research has been performed on terminally differentiating post-confluent cells.

This study sought to assess the effects of highly pure MWCNTs on primary human bronchial epithelial cell (BEC) cultures, that may not be apparent at the higher cytotoxic doses or shorter time points usually studied. We used primary cells from healthy human volunteers and MWCNT treatments between $0.7 \mu \mathrm{g} / \mathrm{mL}$ and $12 \mu \mathrm{g} / \mathrm{mL}$, and assessed the cells at both one and 7 days post exposure. This permitted a better replication of extended exposures with regard to human cells, which is more relevant as a proxy of environmental or occupational human exposure. MWCNTs taken into the lungs are known to persist in these tissues for weeks, ${ }^{10,17}$ so assessing the effect that this persistent material may have at the cellular level long after the initial exposure is a relevant avenue of study.

One important metric of pulmonary health is the ability of the BEC layer to serve as a barrier between inhaled air and the more vulnerable endothelial cells and interstitium. The barrier function of an epithelial monolayer relies on tight junctions between adjacent cells, facilitated by zona occludens 1 (tight junction protein 1) and occludins, among other transmembrane proteins. ${ }^{18}$ As these tight junctions fail in response to an environmental stressor, electrolytes are able to penetrate the gaps between cells more readily, and this can be measured by passing an electrical AC current through the cell monolayer and monitoring the impedance to the current. ${ }^{19}$ Because the reduction of barrier function in the epithelium of the human airway can result in increased penetration of airborne particulates and subsequent pulmonary injury, edema, and infection, ${ }^{20}$ barrier function is an important endpoint in toxicological studies of epithelial cells.

Our results suggest that MWCNTs negatively impact the ability of human airway epithelium to form a monolayer barrier even at doses that are not cytotoxic. Associated with this loss of barrier function is altered cell morphology, breakdown of tight junctions, and cytoskeletal disruption, that are not found in cells exposed to nanographitized mesoporous carbon, a chemically similar nanoparticle. MWCNTs may therefore be hazardous to pulmonary health in a manner not common to other fine or ultrafine airborne particulates.

\section{Materials and methods} Human bronchial epithelial primary cells and culture

Primary airway epithelial cells were obtained via bronchoscopy from healthy human volunteers. Cells from brushes were transferred to vented T-flasks and grown to passage 3. Cultures were frozen in recovery freezing medium (Invitrogen, Carlsbad, CA, USA) and stored in liquid nitrogen. Frozen P3 cells were thawed and resuspended in bronchial epithelial growth medium (BEGM; Lonza, Walkersville, MD, USA) before being seeded at $>4,000$ cells $/ \mathrm{cm}^{2}$ on fibronectin/collagencoated plasticware. BEGM consisted of LHC-9 medium with additional supplements of $0.1 \mathrm{ng} / \mathrm{mL}$ retinoic acid, $5 \mu \mathrm{g} / \mathrm{mL}$ insulin, $0.5 \mu \mathrm{g} / \mathrm{mL}$ hydrocortisone, $10 \mu \mathrm{g} / \mathrm{mL}$ transferrin, $6.5 \mathrm{ng} / \mathrm{mL}$ triiodothyronine, $0.5 \mu \mathrm{g} / \mathrm{mL}$ epinephrine, $5 \mathrm{ng} / \mathrm{mL}$ human epidermal growth factor, $50 \mu \mathrm{g} / \mathrm{mL}$ gentamicin, and $0.4 \%$ bovine pituitary extract. Plasticware was pretreated with a fibronectin-containing substrate $(10 \mu \mathrm{g} / \mathrm{mL}$ fibronectin, $10 \mu \mathrm{g} / \mathrm{mL}$ bovine serum albumin, and $30 \mu \mathrm{g} / \mathrm{mL}$ collagen) in sterile phosphate-buffered saline and allowed to incubate at $37^{\circ} \mathrm{C}$ overnight. This solution was then exposed to an ultraviolet lamp for 10 minutes and aspirated prior to addition of cell suspension to the plasticware. Cell cultures were given fresh BEGM every other day and allowed to reach confluence in six-well cell culture plates $\left(\sim 9.5 \mathrm{~cm}^{2} /\right.$ well; Corning, New York, NY, USA) before they were treated, which took place 4-5 days from the day of seeding.

\section{MWCNT submerged culture treatment}

The MWCNTs used in these studies were sourced from Helix Material Solutions (Richardson, TX, USA), and generously donated to us by Dr James Bonner. According to the manufacturer, these MWCNTs are over 95\% pure, endotoxin-free, and contain less than $0.5 \%$ catalyst metals (iron and nickel). The average tube diameter is $10-30 \mathrm{nM}$ and they range in length from $500 \mathrm{nM}$ to $40 \mu \mathrm{M}$. Independent analysis performed by Millennium Research Laboratories ${ }^{10}$ confirmed their purity by thermogravimetric analysis and the sizes were determined to be $30-50 \mathrm{nM}$ in diameter and $300 \mathrm{nM}$ to $50 \mu \mathrm{M}$ in length by transmission electron microscopy (TEM). Brunauer-Emmett-Teller analysis gave a surface area of $109.29 \mathrm{~m}^{2} / \mathrm{g}$. Graphitized mesoporous carbon was purchased from Sigma-Aldrich (Cat\#699624, Lot\#MKBH0461V; St Louis, MO, USA) and used as a shape control in these studies. Analysis of this lot by the manufacturer determined the graphitized carbon to be $>99.95 \%$ pure and the surface area to be $77.0 \mathrm{~m}^{2} / \mathrm{g}$.

Dry nanoparticle powder was suspended at $2 \mathrm{mg} / \mathrm{mL}$ in dispersion medium $(10 \mu \mathrm{g} / \mathrm{mL}$ dipalmitoylphosphatidylcholine, 
$1 \%$ bovine serum albumin in BEGM). The microcentrifuge tubes containing the nanoparticle suspensions were then sonicated in a cup horn at amplitude 100 five times for 3 minutes each. Serial dilutions were then made to $12 \mu \mathrm{g} /$ $\mathrm{mL}, 3 \mu \mathrm{g} / \mathrm{mL}, 1.5 \mu \mathrm{g} / \mathrm{mL}$, and $0.75 \mu \mathrm{g} / \mathrm{mL}$ in dispersion medium. These dilutions were then also sonicated again (same conditions) immediately prior to being applied to the confluent cell cultures. The negative control received sonicated dispersion medium only. Measurements of the hydrodynamic diameter of the nanomaterial suspensions used in this study (as measured by dynamic light scattering) can be found in Figure 1. The zeta potential of the MWNCTs in dispersion medium was found to be $-13 \pm 2$ $\mathrm{mV}$, as measured by a Zetasizer Nano (Malvern Instruments, Malvern, UK).

The BECs were treated with nanoparticles once at day 0 , and the medium was refreshed on day 1 and every 2 days following treatment (days 3 and 5), with two exceptions.
The transepithelial impedance assay was greatly perturbed by refreshing the medium, so the medium was only refreshed at 3 days following the initial 24-hour exposure. The cytotoxicity assays required a consistent time interval of cell death, so the medium was always refreshed 24 hours prior to assay. This necessitated an additional refreshing of medium at day 6 , in addition to the above schedule, for the lactate dehydrogenase (LDH) and trypan blue assays. No additional nanoparticles were added to the cells between day 0 and when the cells were harvested/counted. TEM was used to verify that the MWCNTs were entering the cells and remaining there after the treatment suspensions were removed 24 hours later (Figure 2).

During the 24-hour period in which the BECs were exposed to the nanoparticle-containing medium, the nanomaterials did not settle completely out of suspension. This is why doses are represented in this study as $\mu \mathrm{g} / \mathrm{mL}$ rather than as $\mu \mathrm{g} / \mathrm{cm}^{2}$. However, the conversions using culture vessel surface area from $12,3,1.5$, and $0.75 \mu \mathrm{g} / \mathrm{mL}$ would be $3.8,0.95$,
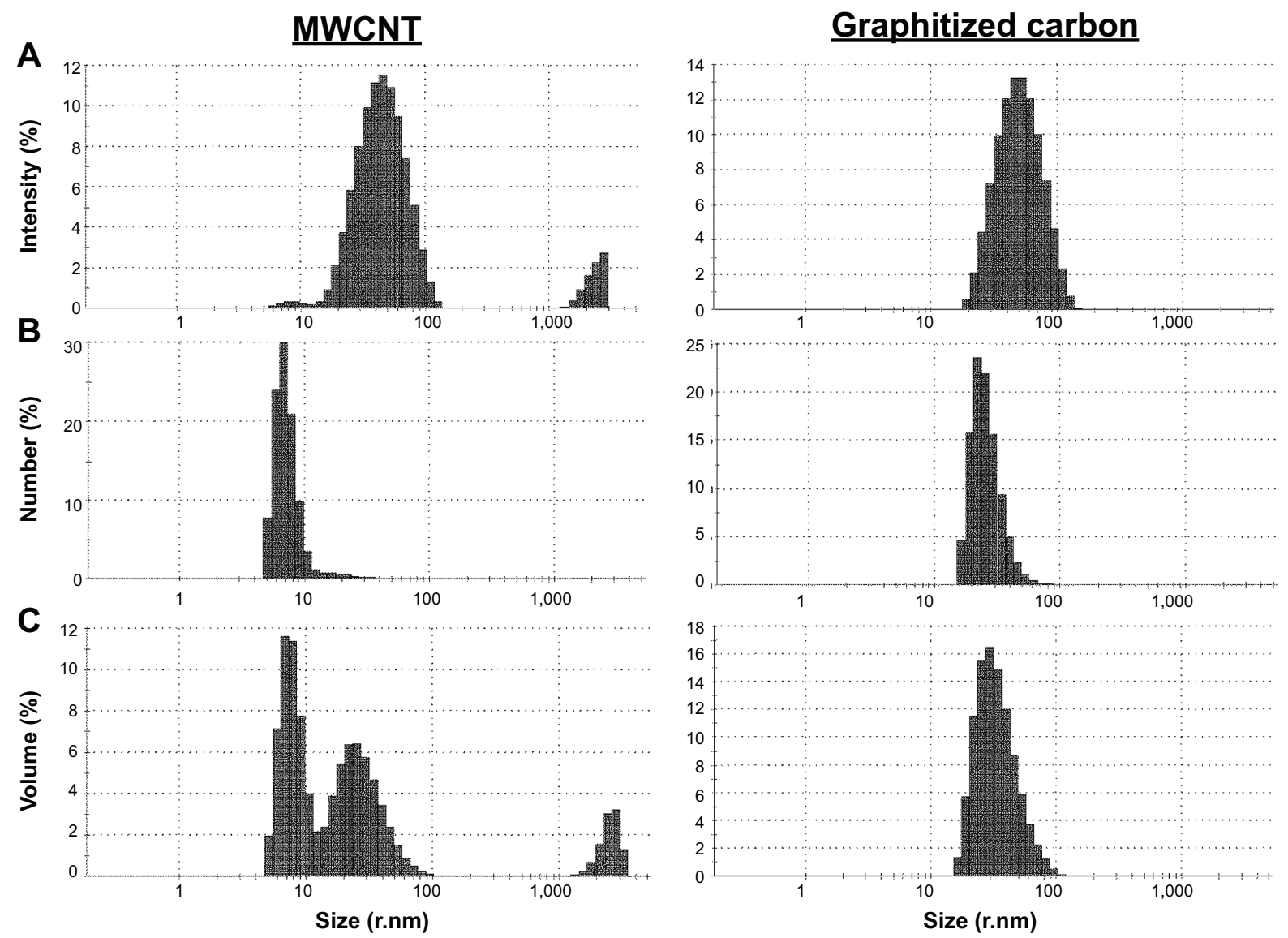

Figure I Dynamic light scattering analysis of nanoparticle suspensions.

Notes: Results of DLS measurements on MWCNT and graphitized carbon suspensions immediately following sonication. (A) Intensity measurement, indicating the total percent of beam scattering by size category. (B) Number measurement, calculated using Mie Theory. This graph represents the total percentage of the nanoparticle aggregates/agglomerates, by number, that fall into each size category. Nearly all of the nanoparticles were below $100 \mathrm{nM}$ in hydrodynamic diameter by number. (C) Volume/ mass measurement, calculated using Mie Theory. The last graph represents the total percentage of the nanoparticle mass that falls within each size category. Less than I0\% of the total MWCNT mass is sequestered in large, >I $\mu$ M agglomerates. The remaining nanomaterial mass falls beneath the $100 \mathrm{nM}$ "nano" threshold.

Abbreviations: MWCNTs, multiwalled carbon nanotubes; DLS, dynamic light scattering. 


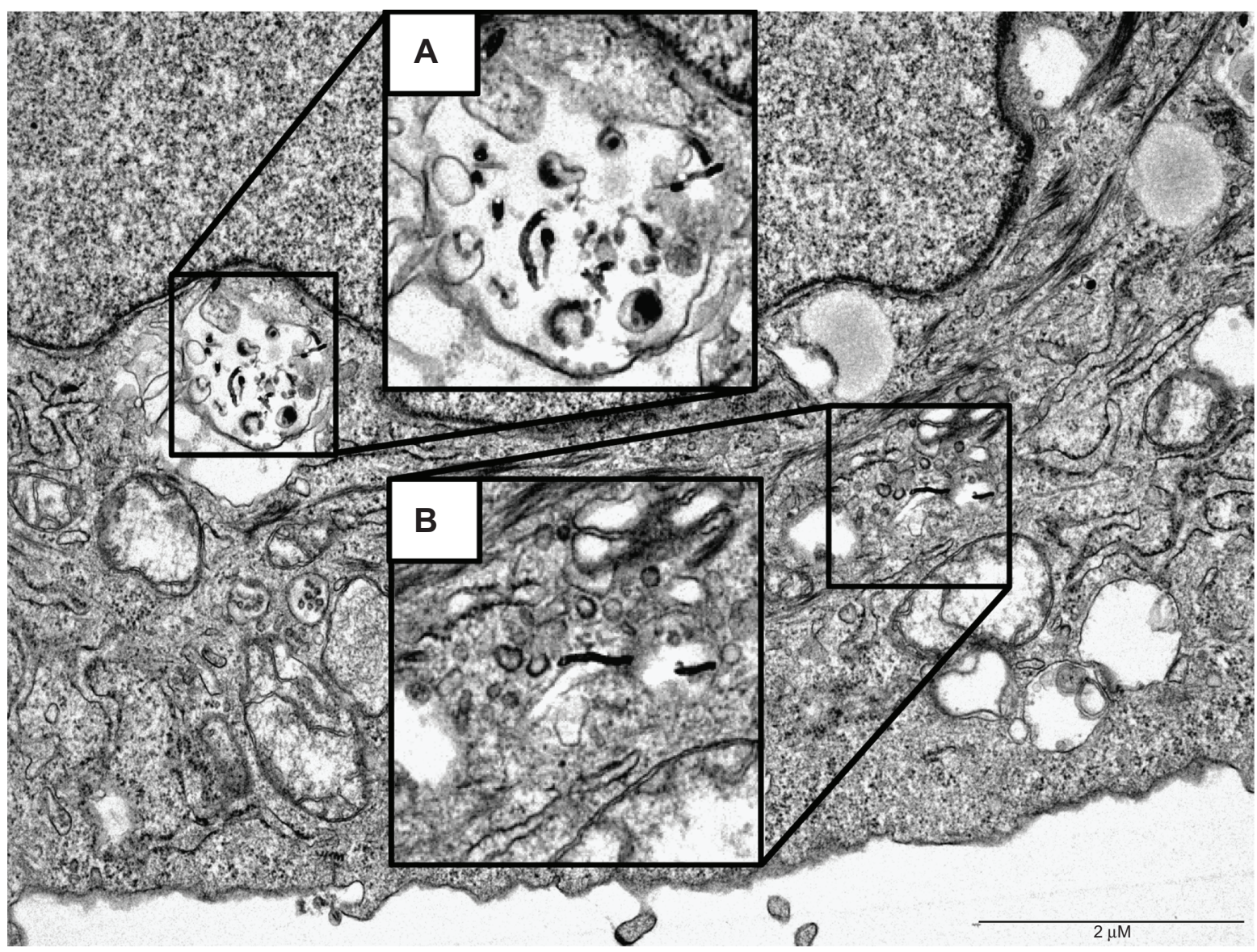

Figure 2 TEM image of MWCNTs inside bronchial epithelial cell 24 hours post exposure.

Notes: Image taken shows the presence of MWCNTs inside the cell after the removal of nanoparticle media suspension. Demonstrated here are MWCNTs that have been both taken up into phagosomes (Inset $\mathbf{A}$ ) and that are free in the cytoplasm (Inset B), presumably as a result of direct penetration of the cell or phagosome membrane. This image helps to explain why effects on the cell culture continue to progress for days after the removal of MWCNT suspensions and subsequent media refreshes, as the non-agglomerated fibers persist in the cell.

Abbreviations: MWCNTs, multiwalled carbon nanotubes; TEM, transmission electron microscopy.

0.24 , and $0.06 \mu \mathrm{g} / \mathrm{cm}^{2}$, respectively. Because all time points in this study involved the same 24-hour exposure period, the lack of complete settling is internally controlled for.

\section{Transepithelial electrical impedance}

Electrical impedance across the epithelial monolayer was measured using an electric cell-substrate impedance sensing (ECIS) instrument from Applied Biophysics (Troy, NY, USA). Cells were seeded at 10,000 cells $/ \mathrm{cm}^{2}$ on precoated E10+ eight-chamber arrays and allowed to grow to confluence prior to treatment. The E10+ arrays contained gold electrodes on the cell growth surface that allowed electrical impedance measurements across the monolayer to be made and recorded continuously during the treatment period. Cells were treated with graphitized carbon, MWCNTs, or dispersion medium as the negative control at day 0 (with four replicates for each treatment group) and monitored continually for 7 days, with a single refreshment of medium.

\section{Lactate dehydrogenase assay}

Cytotoxicity in the treated cells was measured using the rate of $\mathrm{LDH}$ release into the supernatant medium as a proxy. LDH content in the medium was measured by a CytoTox-96 kit (Promega, Madison, WI, USA) utilizing the reduction of tetrazolium salt into an aqueous formazan dye product, which was then quantified on a spectrophotometer at $492 \mathrm{nM}$ as per the manufacturer's protocol. The potential interaction of nanotubes with the formazan dye product has been described by previous researchers, ${ }^{21}$ so an acellular test of this interaction using the LDH positive control provided by the manufacturer was performed prior to running this study. The results of this acellular test (not shown) confirmed that the confounding impact of the nanotubes and graphitized carbon was not significant or noticeable at the doses used. Cells were treated at day 0 as described in MWCNT submerged culture treatment and then harvested at days 1,4 , and 7 . The most recent feeding always occurred 24 hours prior to harvest, so each LDH measurement represents 
the accumulated LDH release during the previous 24-hour time period. Hydrogen peroxide $(1 \mathrm{mM})$ was used as a positive control for cell death. Four replicates of each treatment group were measured and their absorbance at $492 \mathrm{nM}$ was averaged.

\section{Trypan blue exclusion direct cell counts}

Cell viability was also measured in treated cells via direct cell counts under microscopy using a hemocytometer. Supernatants were removed from the wells and stored on ice, while cells were lifted from the well surface using trypsin/ethylenediaminetetraacetic acid solution and soybean trypsin inhibitor (Sigma). Cell suspension in inhibited trypsin was added back to the supernatant containing the dead cells, and trypan blue dye (Sigma) was added 1:5 to stain dead or nonviable cells. Suspensions were stored on ice as cell counts were made on the hemocytometer, and counts from four replicates of each treatment group were averaged.

\section{Quantitative PCR}

Total RNA was harvested from adherent cell cultures using an RNEasy Midi Kit (Qiagen, Valencia, CA, USA) with DNAse treatment. Total RNA was then measured by NanoDrop and converted to complementary DNA using Invitrogen's SuperScript III kit and oligo dTs, all using the manufacturers' protocols. Power SYBR Green Master Mix (Applied Biosystems, Waltham, MA, USA) and the following primers were used for quantitative polymerase chain reaction $(\mathrm{PCR})$ at final concentrations of $900 \mathrm{nM}$ : ubiquitin $\mathrm{C}$ (UBC) 5'-ACGCACCCTGTCTGACTACA; UBC 3'-ACCTCTAAGACGGAGCACCA; vimentin 5'-GGAAGAGAACTTTGCCGTTGAA; vimentin 3'GTGACGAGCCATTTCCTCCTT; alpha-smooth muscle actin ( $\alpha$-SMA) 5'-CTGGCATCGTGCTGGACTCT; $\alpha$-SMA 3'-GATCTCGGCCAGCCAGATC; fibronectin 5'-GAGCTATTCCCTGCACCTGATG; fibronectin 3'-CGTGCAAGGCAACCACACT.

Data were collected on a Stratagene Mx3005P realtime sequencer (Agilent Technologies, Santa Clara, CA, USA). Fold expression of target genes was determined by ddCt analysis, comparing expression UBC and normalizing to dispersion medium-treated controls. Each fold expression represents an average of three donors per treatment group.

\section{Western blot}

Protein was harvested from cell cultures using RIPA lysis and extraction buffer (Thermo Scientific, Waltham,
MA, USA) and stored at $-80^{\circ} \mathrm{C}$ with protease inhibitor cocktail (Sigma) at 1:100 dilution. Protein was quantified by absorbance at $562 \mathrm{nM}$ using a bicinchoninic acid assay compared against a standard curve of increasing concentrations of bovine serum albumin. Protein was electrophoretically separated on a $4 \%-12 \%$ bis-tris polyacrylamide gel and transferred to a polyvinylidene difluoride membrane. Membranes were blocked for 30 minutes at room temperature in 5\% bovine serum albumin in phosphate-buffered saline and 0.1\% Tween-20 (wash buffer). Rabbit monoclonal primary antibodies against E-cadherin and vimentin (Cell Signaling Technologies, Danvers, MA, USA) were separately applied for 3 hours at 1:1,000 at room temperature on a shaker. Rabbit polyclonal primary antibodies against $\alpha$-SMA (Epitomics, Cambridge, MA, USA) and fibronectin (Santa Cruz Biotechnology, Sanata Cruz, CA, USA) were applied for 4 hours at 1:333 and 1:1,000 wash buffer, respectively. After washing three times with wash buffer, goat anti-rabbit horseradish peroxidase-conjugated secondary antibody (Cell Signaling Technologies) was applied at 1:5,000 for one hour at room temperature and shaking. The membranes were then washed three times before applying ECL Prime (Invitrogen) for 5 minutes. Membranes were imaged on a G-Box digital imaging system and Gene-Sys densitometry software was used to quantify the bands. Glyceraldehyde 3-phosphate dehydrogenase expression was used as a loading control, and was resolved using a rabbit monoclonal antibody (Cell Signaling Technologies) at 1:1,000, with the secondary antibody described above.

\section{Immunofluorescent staining}

BECs were grown to confluence on chamber slides (coated with fibronectin-containing substrate) prior to treatment with nanomaterials. After 7 days of treatment, cells were fixed on the slide for 10 minutes in 4\% paraformaldehyde, washed three times with phosphate-buffered saline, treated with $50 \mathrm{mM}$ ammonium chloride in phosphate-buffered saline for 10 minutes, and then washed again. Actin fibers were stained using Alexa488-conjugated phalloidin (Invitrogen) diluted 1:40 in phosphate-buffered saline with a DRAQ5 nuclear stain (Cell Signaling Technology) diluted 1:1,000. Fixed cells were incubated with stain at room temperature for 20 minutes, after which time they were washed with phosphate-buffered saline and mounted using Prolong Gold antifade reagent (Invitrogen). Microtubules were stained using Alexa488 primary-conjugated mouse anti- $\alpha$-tubulin monoclonal antibody (Invitrogen) diluted to $3 \mu \mathrm{g} / \mathrm{mL}$ in 
phosphate-buffered saline. Cells were permeabilized with $0.5 \%$ Triton- $\mathrm{X}$ in phosphate-buffered saline for 5 minutes, washed, then blocked with $5 \%$ bovine serum albumin for 30 minutes at room temperature prior to incubation with the antibody for one hour (also at room temperature). Tight junction proteins, zona occludens 1 and occludin, were separately stained, with the same permeabilization and blocking steps. Alexa594 primary-conjugated mouse anti-zona occludens 1 monoclonal antibody (Invitrogen) was diluted to $3 \mu \mathrm{g} / \mathrm{mL}$ in phosphate-buffered saline and allowed to incubate at room temperature for one hour. Rabbit anti-occludin polyclonal antibody (Abcam, Cambridge, MA, USA) was diluted to $1 \mu \mathrm{g} / \mathrm{mL}$ in $1 \%$ bovine serum albumin/phosphate-buffered saline and allowed to incubate at $4{ }^{\circ} \mathrm{C}$ overnight. Alexa488-conjugated anti-rabbit secondary antibody (Invitrogen) diluted 1:200 in 1\% bovine serum albumin/phosphate-buffered saline was applied for one hour at room temperature. Cells were then washed and mounted with Prolong Gold. An LSM 710 confocal microscope (Zeiss, Oberkochen, Germany) was used to obtain images and Z-stacks of the stained cells.

\section{Z-stack summation and analysis}

Quantifying the occludin staining of tight junctions in confocal images presents a challenge as the occludin is translocated to the tight junctions from the cytoplasm, and the total occludin expression changes little during breakdown of the junctions. To overcome this, randomly selected occludinstained confocal Z-stacks (eight from cells treated with the control vehicle and eight treated with MWCNT $3 \mu \mathrm{g} / \mathrm{mL}$ ) were collapsed into two-dimensional summation images of the $12 \mu \mathrm{M}$-thick section in the middle of each monolayer. This section excluded only the apical and basal cell surfaces to reduce background, and allowed for a volumetric comparison of an equal number of Z-slices. Background staining was subtracted by the rolling ball method with a 10 pixel radius. A binary image was then created by eliminating all pixels of intensity 17 or less, and those pixels that remained were primarily located in tight junctions. The total pixel area of each binary summation image was measured by Image J software and the eight image areas per treatment were averaged and compared.

\section{Statistical analysis}

All data are presented as the mean \pm standard deviation. Significance between treatment groups was determined using one-way analysis of variance. A $P$-value less than 0.05 indicated statistical significance. Corrections for multiple comparisons were made using Bonferroni's post hoc test. Unless otherwise noted, statistical analyses were based on four experimental replicates.

\section{Results \\ Phase-contrast microscopy}

Phase-contrast images of BECs treated with $3 \mu \mathrm{g} / \mathrm{mL}$ MWCNTs began to reveal altered cell morphology within 4-5 days post exposure, becoming clearly apparent by day 7 (Figure 3A). After treatment with MWCNTs, most of the cells lost their cuboidal organization, taking on a spindle-shaped, fibroblastoid appearance. This effect was not observed in cells treated with graphitized carbon.

\section{Transepithelial electrical impedance}

The loss of cuboidal organization and altered cell morphology correlated with a significant reduction in barrier function by the epithelial monolayer (Figures 3B and C), as measured by ECIS. Electrical impedance through the treated cell monolayers remained similar to that of the control cells for the first 2-3 days, but quickly declined over the following 4-7 days. By day 7 post exposure, cells treated with $3 \mu \mathrm{g} / \mathrm{mL}$ MWCNTs averaged only $45.2 \%$ of the electrical impedance of the control cells, and the $12 \mu \mathrm{g} / \mathrm{mL}$ MWCNT dose reduced electrical impedance to near acellular levels. By contrast, $12 \mu \mathrm{g} / \mathrm{mL}$ graphitized carbon resulted in no significant reduction in impedance from the vehicle control. Earlier acellular studies verified that MWCNTs and graphitized carbon do not alter impedance in the absence of cells (data not shown), so nanomaterial conductivity was not a confounding issue in this experiment.

\section{Epithelial-mesenchymal transition marker expression}

Epithelial-mesenchymal transition (EMT) was investigated as a potential mechanism behind the observed morphology by examining the expression of classic mesenchymal markers. Analysis of E-cadherin, vimentin, $\alpha$-SMA, and fibronectin protein expression in BECs by Western blotting revealed no significant difference between the BECs treated with MWCNT $3 \mu \mathrm{g} / \mathrm{mL}$ and those treated with dispersion medium or untreated controls. Vimentin, $\alpha$-SMA, and fibronectin were not substantially expressed in any of these treatments and E-cadherin was not significantly downregulated (Figure 4A).Vimentin, $\alpha$-SMA, and fibronectin were all transcriptionally expressed at levels similar to those in dispersion medium and graphitized carbon-treated controls at the $0.75 \mu \mathrm{g} / \mathrm{mL}$ and $3 \mu \mathrm{g} / \mathrm{mL}$ MWCNT doses (Figure 4B), indicating that the cells did not undergo EMT following 
A

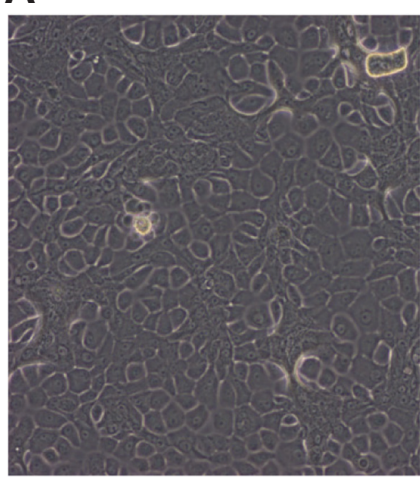

Control vehicle (CoV)

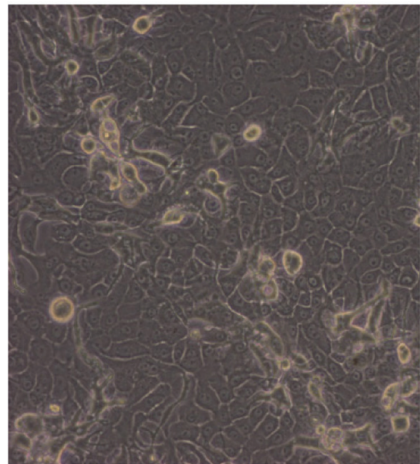

MWCNT $1.5 \mu \mathrm{g} / \mathrm{mL}$ (MW 1.5)

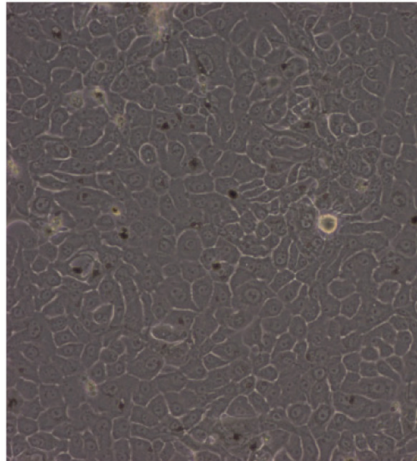

Graphitized carbon $12 \mu \mathrm{g} / \mathrm{mL}$ (NG 12)

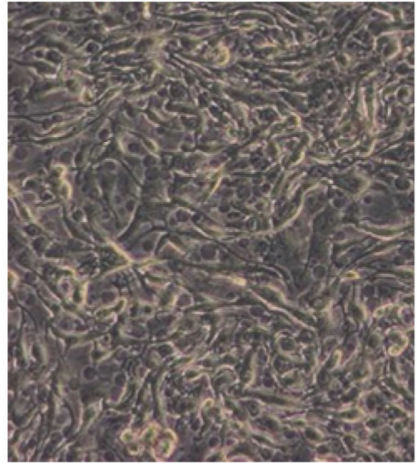

MWCNT $3 \mu \mathrm{g} / \mathrm{mL}$ (MW 3)

C

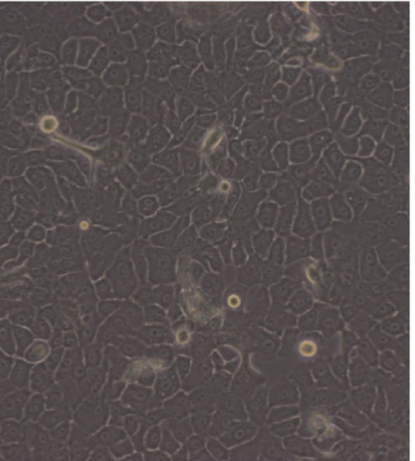

MWCNT $0.75 \mu \mathrm{g} / \mathrm{mL}$ (MW 0.75)

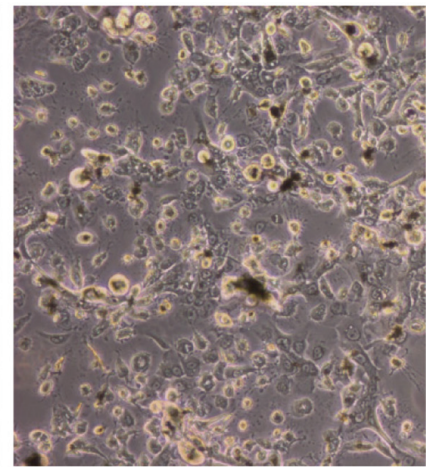

MWCNT $12 \mu \mathrm{g} / \mathrm{mL}$ (MW 12)
B

Electrical impedance in BEC monolayers

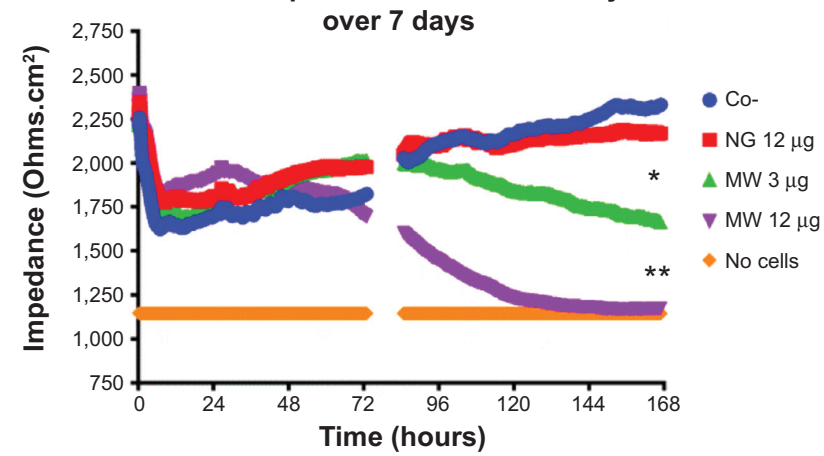

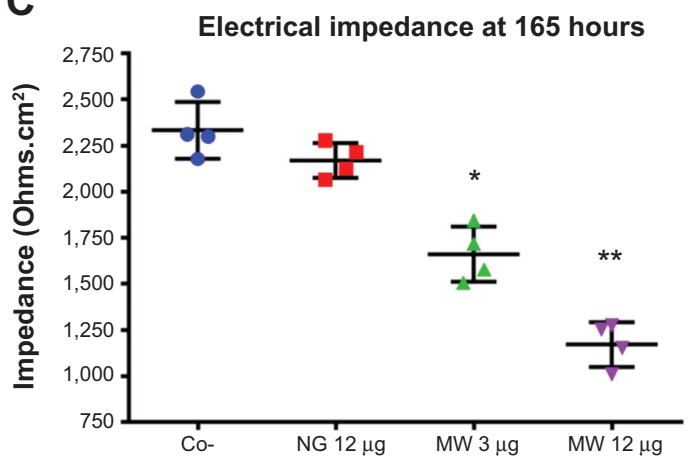

Figure 3 Loss of epithelial monolayer and barrier function.

Notes: (A) Image comparison in phase contrast of bronchial epithelial cells (BECs) 7 days post-exposure (I0× magnification). (B) Electrical impedance through BEC monolayer continuously measured by ECIS from days I-7. At day 3 , the media was refreshed and the resulting impedance fluctuations were omitted to better illustrate the pattern. (C) Electrical impedance of individual experimental runs taken at 165 hours ( 7 days) post-exposure. This is the same data from graph B, represented differently to show the experimental consistency. $* P<0.05, * * p<0.01$.

Abbreviations: MWCNT, multiwalled carbon nanotube; ECIS, electric cell-substrate impedance sensing.

treatment. No statistically significant differences were found in expression of any of these markers.

\section{Cytotoxicity assays}

After observing profound effects in cell morphology and impedance, we analyzed LDH release and trypan blue uptake in treated cells to confirm that our doses did not induce cell death at the measured time points. Absorbance measurements of LDH released in supernatant medium indicated no elevated cytotoxicity at the $3 \mu \mathrm{g} / \mathrm{mL}$ MWCNT dose or lower at any of the measured time points (Figure 5A). At day 1, cells treated with $12 \mu \mathrm{g} / \mathrm{mL}$ MWCNT showed no significantly elevated toxicity, whereas by day 4 , cell death had exceeded that in $1 \mathrm{mM} \mathrm{H}_{2} \mathrm{O}_{2}$ positive controls. By day 7, too few cells remained in the $12 \mu \mathrm{g} / \mathrm{mL}$ MWCNT-treated wells to make LDH measurements. Cells treated with $12 \mu \mathrm{g} / \mathrm{mL}$ graphitized 
A

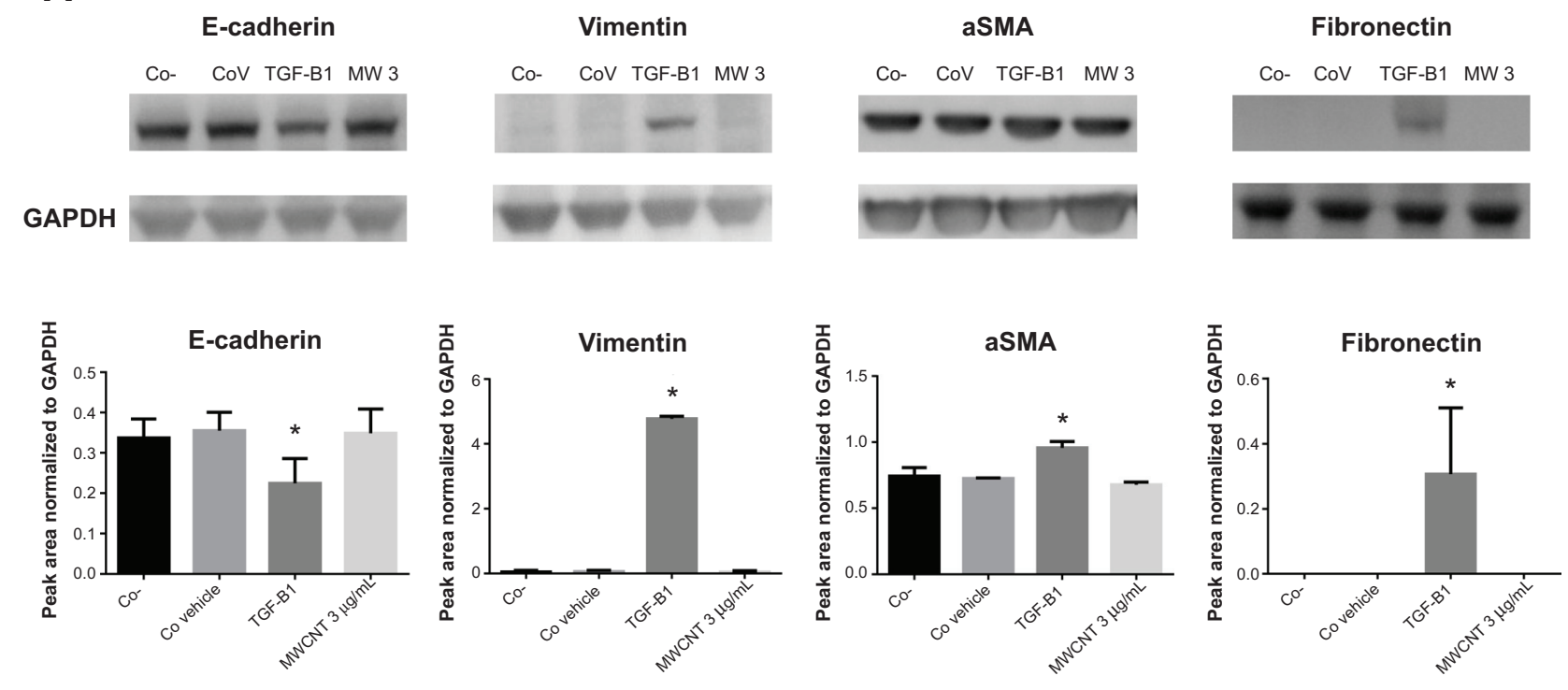

B
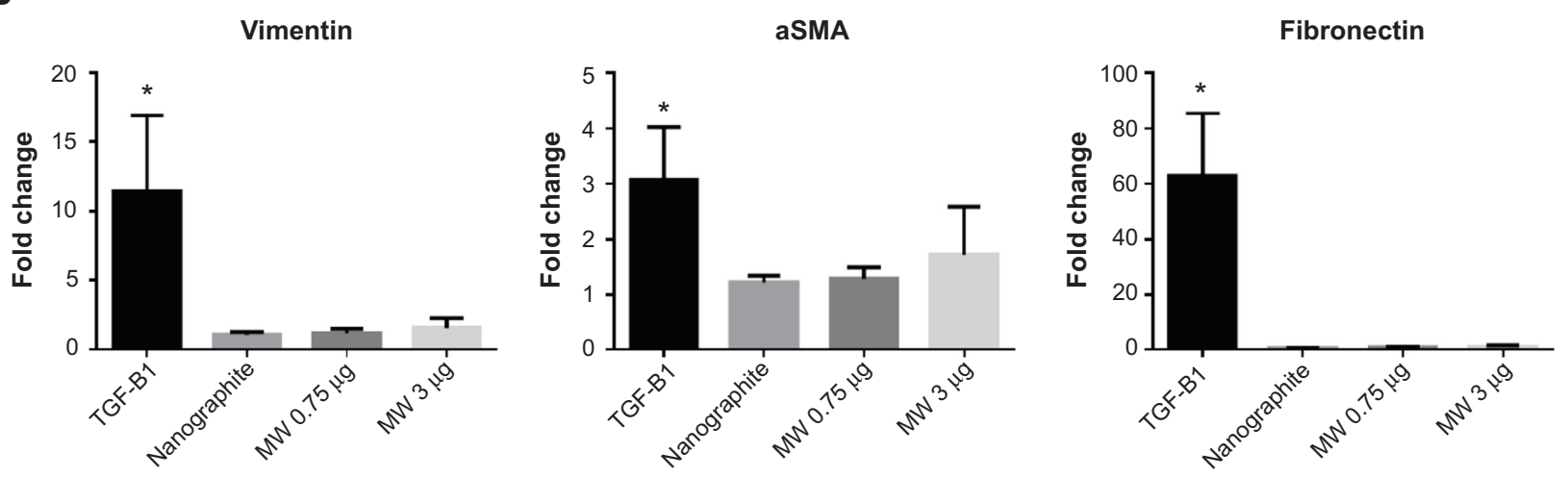

Figure 4 EMT markers not expressed in exposed cells.

Notes: (A) Western blotting for E-cadherin, vimentin, aSMA, and fibronectin expression in bronchial epithelial cells (BECs) exposed to $3 \mu \mathrm{g} / \mathrm{mL}$ MWCNTs. Both a mediaonly negative control (Co-) and dispersion-media negative control (CoV) were used for comparison. TGF-BI (I0 ng/mL) was used as a positive control for EMT. Peak area of bands determined by densitometry software was normalized to GAPDH loading control. Experiments performed in triplicate, a representative blot image is shown. (B) Gene expression of EMT markers in exposed BECs, as determined by quantitative PCR. TGF-BI was again used as a positive control, and $3 \mu \mathrm{g} / \mathrm{mL}$ nanographite as a shape control. Ct values were subtracted from dispersion-media negative controls and normalized to ubiquitin-C. ANOVA $* P<0.05, n=4$.

Abbreviations: MWCNT, multiwalled carbon nanotube; EMT, epithelial-mesenchymal transition; PCR, polymerase chain reaction; TGF-BI, transforming growth factor beta I; aSMA, alpha smooth muscle actin; Ct, cycles to reach threshold value; ANOVA, analysis of variance.

carbon had no significantly elevated cytotoxicity at any time point. Direct hemocytometer counts of trypan blue-stained cells gave results comparable with the LDH measurements (Figure 5B). Graphitized carbon and doses of MWCNT $3 \mu \mathrm{g} /$ $\mathrm{mL}$ and lower did not induce significant elevation of trypan blue uptake by day 7 , whereas $12 \mu \mathrm{g} / \mathrm{mL}$ MWCNTs resulted in extensive cell death exceeding the positive control after 4 days. While these results are not verification that the $3 \mu \mathrm{g} /$ mL MWCNT dose could never become toxic given sufficient time, they are evidence that the day 7 impedance results were not due to cytotoxicity at this dose.

\section{Phalloidin and tubulin stains}

Having observed no cell death on day 7 at the $3 \mu \mathrm{g} / \mathrm{mL}$ MWCNT dose, we stained the cytoskeleton and tight junctions of BECs exposed to this dose. Confocal microscopy of the cytoskeletal network staining is depicted in Figure 6A. In treated BECs with a spindle-shaped morphology, phalloidin poorly stained the F-actin fibers compared with adherent control cells. BECs treated with MWCNT $3 \mu \mathrm{g} / \mathrm{mL}$ that still retained their morphology nonetheless had a microtubule cytoskeleton that was more bundled and less diffuse through the cytoplasm than in the control or graphitized carbon-treated cells, suggesting increased polymerization. These treated cells also expanded in size compared with control cells.

\section{Zona occludens-I and occludin stains}

Confocal microscopy of tight junction staining is depicted in Figure 6B. Both stains showed a reduction in tight 

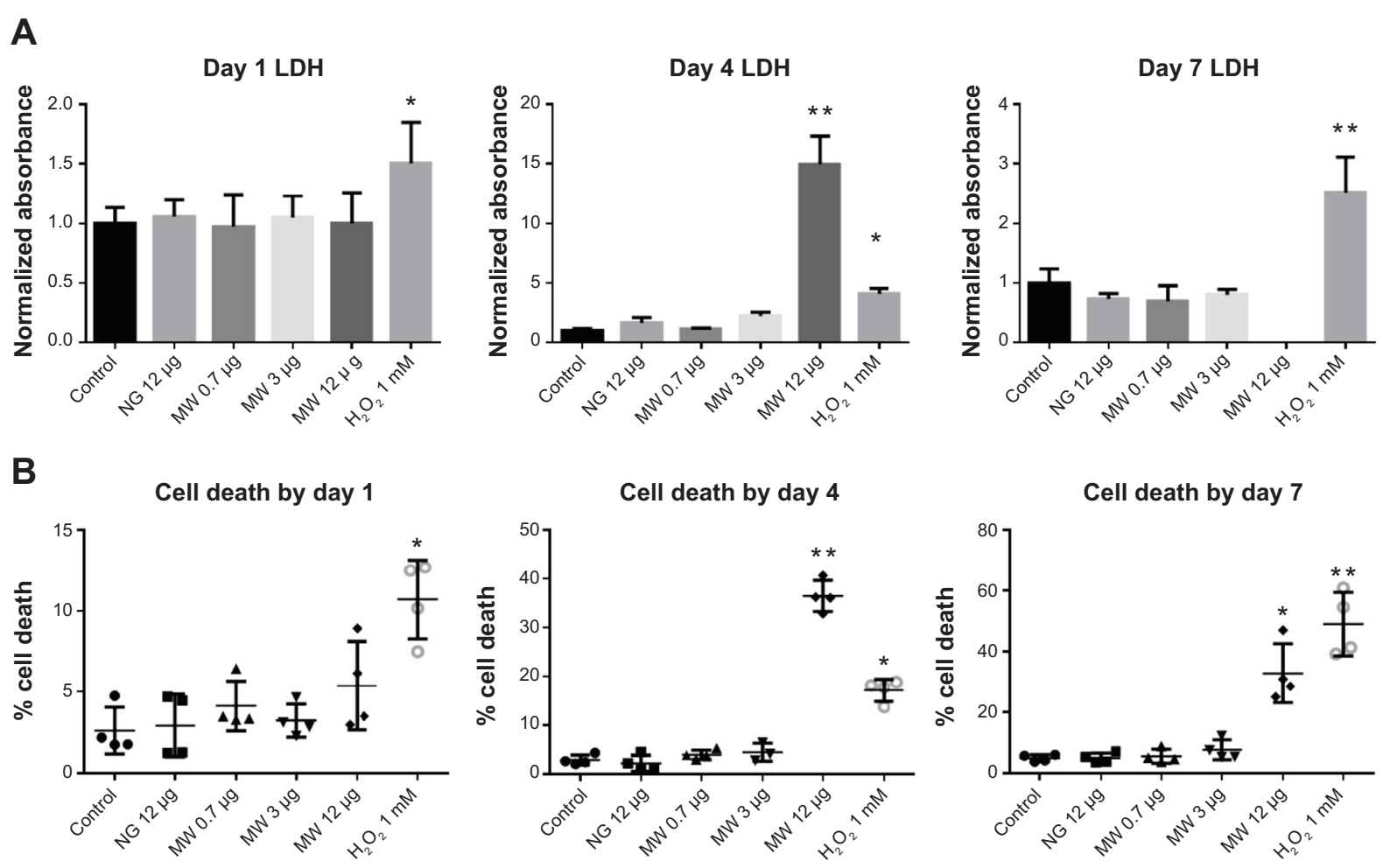

Figure 5 Cytotoxicity of MWCNTs on BECs.

Notes: (A) Lactate dehydrogenase release into supernatant media over previous 24 hours. Absorbance of reduced formazan dye at $490 \mathrm{nM}$ was normalized to the dispersion-media control. Hydrogen peroxide ( $\mathrm{I} \mathrm{mM}$ ) was used as a positive control. The $12 \mu \mathrm{g} / \mathrm{mL} \mathrm{MWCNT}$ dose at day 7 resulted in the loss of so many cells that LDH levels were too low to measure. ANOVA $* P<0.05, * * P<0.000 \mathrm{I}, \mathrm{n}=4$. (B) Percent cell death based on direct counts of live cells stained with trypan blue reagent on days $\mathrm{I}$, 4 and 7 post exposure. Hydrogen peroxide was again used as a positive control. ANOVA $* P<0.05, * * P<0.000 \mathrm{I}, \mathrm{n}=4$.

Abbreviations: LDH, lactate dehydrogenase; BEC, bronchial epithelial cell; MWCNT, multiwalled carbon nanotube; NG, nano graphitized carbon; ANOVA, analysis of variance.

junction formation following 7 days of exposure to MWCNT $3 \mu \mathrm{g} / \mathrm{mL}$. This agrees with the reduction in barrier impedance demonstrated by ECIS in treated cells. The volumetric analysis required collapsing $12 \mu \mathrm{M}$ of confocal Z-stacks into summation images, and an example of one such summation from each treatment is demonstrated in Figure 7A. Profile histograms of $10 \mu \mathrm{M}$-wide horizontal sections of each image demonstrated that tight junctions had pixel intensities of 15-20 (Figure 7B), and so a threshold of 17 was selected to construct a binary image that included primarily tight junctions. The average measured areas of each image (by percent) that remained were compared between control cells and MWCNT $3 \mu \mathrm{g} / \mathrm{mL}$-treated cells (Figure 7C), and the tight junction staining following MWCNT treatment was found to be $50.7 \%$ that of the control treatment, agreeing very well with the ECIS results ( $45.2 \%$ impedance).

\section{Discussion}

This study aimed to determine whether MWCNTs, at low $0.7-12 \mu \mathrm{g} / \mathrm{mL}$ doses over 7 days, could elicit cellular responses in human bronchial epithelium not apparent at doses that are cytotoxic at 24 hours. The results indicate a significantly altered morphology in cells treated with
$3 \mu \mathrm{g} / \mathrm{mL}$ MWCNT (equating to a roughly $0.9 \mu \mathrm{g} / \mathrm{cm}^{2}$ dose per surface area in this study), but not in cells treated with graphitized carbon or control cells treated with dispersion medium. Treated cells appear spindle-shaped and disorganized by 4-7 days post exposure. The $0.7 \mu \mathrm{g} / \mathrm{mL}$ MWCNT dose appears to be insufficient to elicit these changes by day 7 , while the $12 \mu \mathrm{g} / \mathrm{mL}$ dose proved to be strongly cytotoxic before these altered morphologies become apparent. The mechanisms of cytotoxicity at the $12 \mu \mathrm{g} / \mathrm{mL}$ or higher MWCNT doses are being explored in a separate study. The fact that the graphitized carbonshape control did not elicit these same effects at similar mass doses suggests that the tubular shape of the MWCNTs is primarily or entirely responsible for the observed effects. Shape characteristics, such as aspect ratio, have also been implicated in previous studies of nanotube toxicity. ${ }^{22,23}$

The observed morphology change was accompanied by a significant drop in epithelial barrier function, evidenced by both the ECIS data and the tight junction immunostaining. This loss of barrier function in the epithelium of a human airway would pose a risk of pulmonary injury and penetration of nanoparticle aggregates throughout the lung, so this finding is of particular concern. A similarly significant decrease 

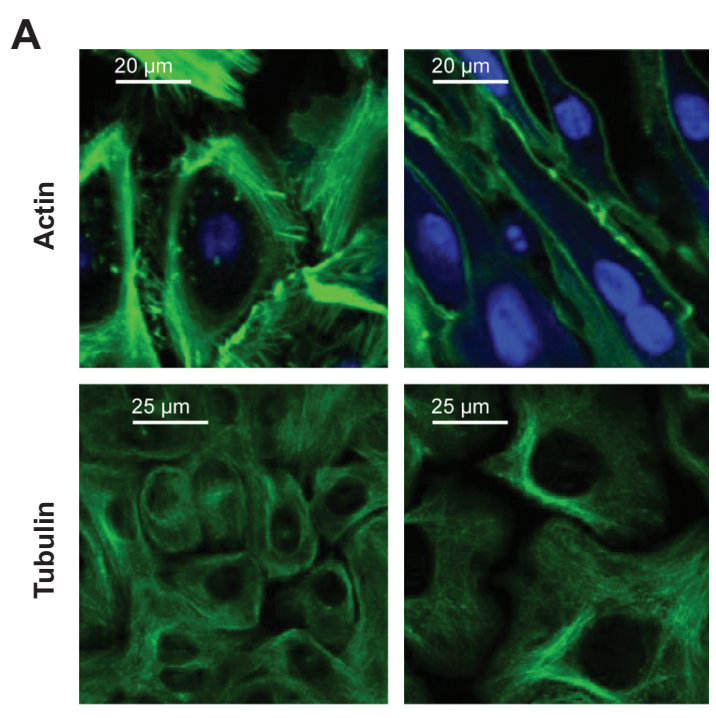

Control

MWCNT $3 \mu \mathrm{g} / \mathrm{mL}$

B
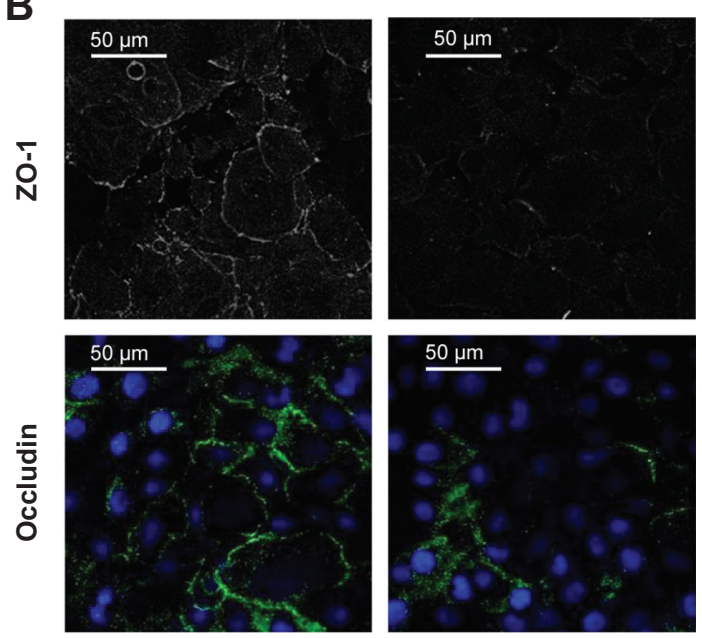

Control

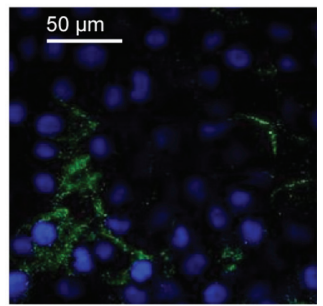

MWCNT $3 \mu \mathrm{g} / \mathrm{mL}$

Figure 6 Immunofluorescent staining of cytoskeleton and tight junctions. Notes: Representative images of BECs following 7 day treatment with $3 \mu \mathrm{g} / \mathrm{mL}$ MWCNTs. (A) Cytoskeletal staining of F-actin by fluorescent-conjugated phalloidin and a-tubulin by conjugated mAb. Phalloidin staining of MWCNT-treated cells is representative of cells with altered morphology (top right), to compare these cells to normal adherent cells (top left). Tubulin staining in MWCNT-treated BECs that remained adherent by day 7 (bottom right) demonstrates the polymerization of the microtubules as well as an increase in cell size. (B) Tight junctions are stained at ZO-I and occludin and imaged using confocal microscopy. ZO-I is shown in grayscale without counterstain. Occludin is shown in false color with DRAQ5 nuclear stain.

Abbreviations: BEC, bronchial epithelial cell; MWCNT, multiwalled carbon nanotube.

in barrier function of epithelial cells exposed to MWCNTs has been described previously, ${ }^{24}$ although the doses used in previous studies were much higher $(100 \mu \mathrm{g} / \mathrm{mL})$ and involved cell lines which are more resilient to nanoparticle toxicity. While higher $(>24 \mu \mathrm{g} / \mathrm{mL})$ doses of MWCNTs are known to be cytotoxic to primary BECs within 24 hours, the breakdown of tight junctions and, consequently, barrier function at the $3 \mu \mathrm{g} / \mathrm{mL}$ dose used in this study has implications for humans chronically exposed to these materials. Long-term exposure

to MWCNTs may result in airway injury at lower doses than would be predicted by acute cytotoxicity studies.

EMT has been demonstrated in the lungs of mice exposed to carbon nanotubes intratracheally. ${ }^{24}$ While EMT would seem a likely mechanism for the observed changes from cuboidal monolayers to disorganized, fibroblastoid cells, our results did not support this. Mesenchymal cells derived through EMT would show greatly upregulated fibronectin, vimentin, and $\alpha$-SMA compared with control epithelial cells, ${ }^{25}$ and we found no differential expression of these mesenchymal markers in the treated cells. Our results do not contradict the previous EMT findings due to the differences between in vivo and in vitro exposures, but we were nonetheless able to determine that EMT was not the mechanism behind the altered morphology observed in our BECs.

Terminal squamous differentiation is a normal consequence of allowing BECs to remain in confluent, submerged culture for several days. ${ }^{26}$ This differentiation effect is apparent in the gradual increase of electrical impedance of the control and graphitized mesoporous carbon-treated BECs in Figure 3B. The initial increase, then decrease to day 1 levels, of impedance in the $3 \mu \mathrm{g} /$ mL MWCNT-treated cells might suggest that this differentiation process is being interfered with by the nanotubes. As squamous differentiation is a terminal event that halts further cell division, ${ }^{27}$ preventing this process in confluent BECs might also explain the overlapping layers of epithelial cells following MWCNT exposure. Verifying that MWCNTs affect squamous differentiation in BECs, as well as establishing a mechanism for this interaction, is beyond the scope of this paper; however, it can be speculated that as the cytoskeletal network is heavily involved in cell differentiation, ${ }^{28}$ MWCNT interactions with the BEC cytoskeleton might also affect their differentiation. The potential of MWCNTs to impair cell differentiation is an ongoing area of our research.

As interactions between MWCNTs and the microtubules of the epithelial cytoskeleton have been described by other researchers, ${ }^{29}$ we explored the possibility of cytoskeletal disruption in our MWCNT-treated BECs. Fluorescent staining of $\alpha$-tubulin bundles in the cytoskeletons of MWCNT-treated and control-treated BECs suggests altered polymerization of the microtubule network in response to treatment with MWCNT $3 \mu \mathrm{g} / \mathrm{mL}$. Microtubules appear to bundle and polymerize in the presence of MWCNTs compared with control cells, and this agrees with previous research ${ }^{30}$ on nanotube/microtubule interactions. This disruption appears to occur early, within 24 hours of treatment and well before cell morphology alterations are evident. The actin cytoskeleton also responds to the MWCNT $3 \mu \mathrm{g} / \mathrm{mL}$ dose, as revealed by phalloidin staining. Treatment with MWCNTs results in a reduction in focal adhesions in cells that remain in a monolayer by day 7 . 
A

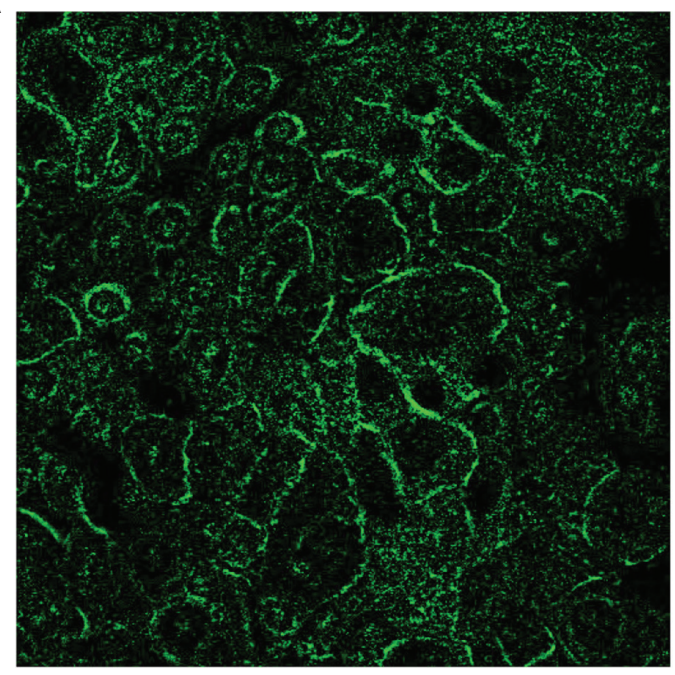

Profile histogram: control vehicle

B

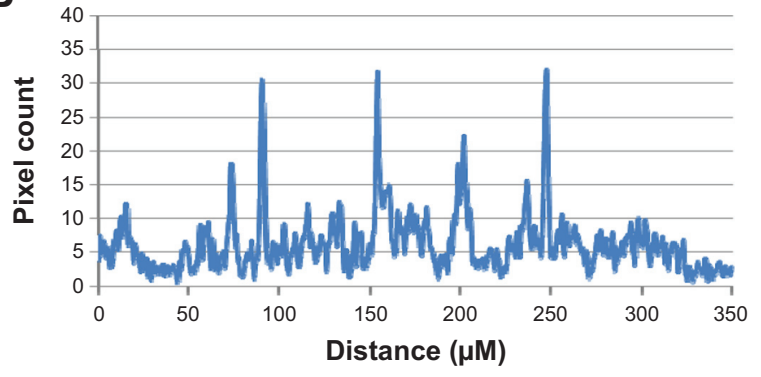

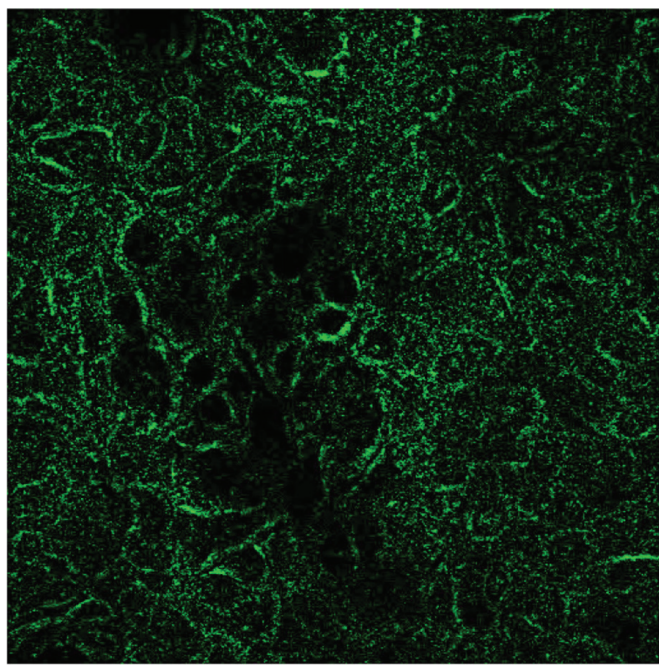

Profile histogram: MWCNT $3 \mu \mathrm{g} / \mathrm{mL}$

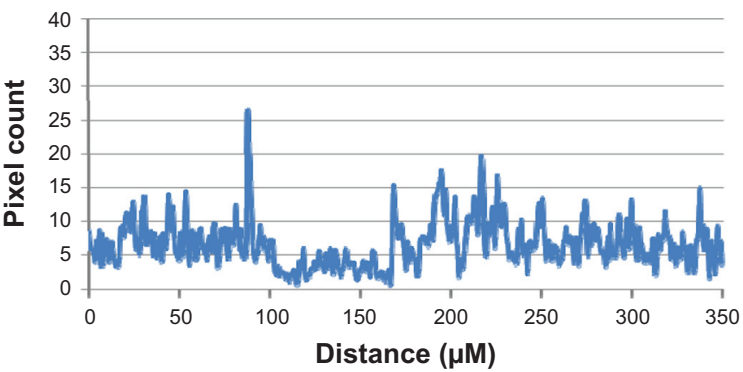

C

Tight junction reduction in BECs treated with MWCNTs for 7 days

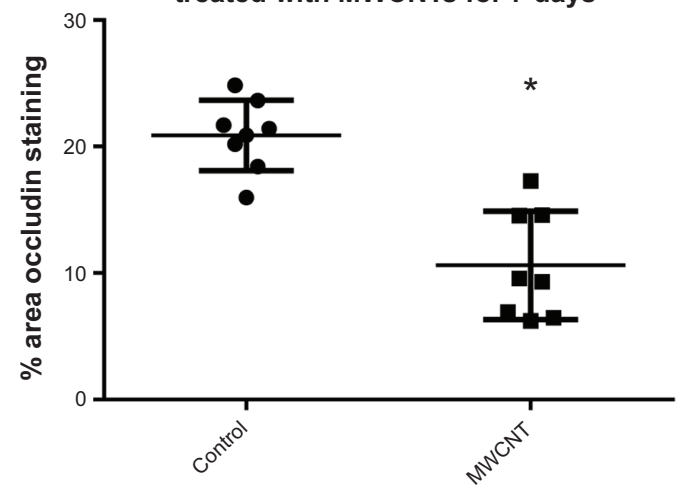

Figure 7 Quantifying loss of tight junctions with occludin confocal images.

Notes: Quantification of tight junction staining began with a summation of confocal z-stacks from a $12 \mu$ M-thick section of cell monolayer, including all but the apical and basal cell surfaces. (A) An example of a summation confocal image from both the control and MWCNT $3 \mu \mathrm{g} / \mathrm{mL}$ treatments. (B) Example profile histograms taken from a $10 \mu \mathrm{M}$-wide horizontal section of the summation images. A peak in this profile would correspond to a concentration of occludin at a tight junction. (C) Particle analysis of pattern of occludin staining based on binary threshold of summation images. The total area of the image that remains after threshold removal of cytoplasmic/nonspecific staining should primarily represent occludin concentrated at tight junctions. The percentage of occludin staining at tight junctions was lower in BECs treated with MWCNT $3 \mu \mathrm{g} / \mathrm{mL}$ for 7 days than in BECs treated with dispersion vehicle alone. *Unpaired 2-tailed $t$-test of 8 summation images, $P<0.000 \mathrm{I}$.

Abbreviations: BEC, bronchial epithelial cell; MWCNT, multiwalled carbon nanotube.

The majority of the cells have left the cuboidal monolayer and taken on a spindle-shaped morphology by this time point, and these altered cells stain very poorly for F-actin. The loss of F-actin microfilaments and focal adhesions may be at least partially responsible for the new morphology of the cell, although whether this is a downstream effect of a differentiation-related event or the direct result of MWCNT interactions with the cytoskeleton will require further research.

We performed this study under submerged culture conditions, rather than fully differentiated air-liquid interfaces. 
Therefore, as in most in vitro systems, the applicability of this study to the human lung is inherently limited. However, these undifferentiated epithelial cells are present in the human lung to replace mucociliary epithelium lost to injury, ${ }^{31}$ and so it is not unlikely that these types of cells could become exposed to inhaled MWCNTs, particularly in an injured lung. This research raises questions about whether morphological alterations similar to those observed in this study could also occur in predifferentiated epithelial cells, or even mature mucociliary cells. To this end, research is currently underway to expose air-liquid interface cultures to these nanoparticles.

Despite these limitations, the results of this study demonstrate that MWCNTs can induce changes in the human bronchial epithelial cytoskeleton and morphology that may pose a health hazard separate from those posed by cytotoxicity and oxidative stress. This effect does not appear to be shared by graphitized mesoporous carbon, and so particular caution may be warranted when using or manufacturing MWCNTenabled products compared with other nanoenabled products where a risk of pulmonary exposure exists.

\section{Acknowledgments}

This research was supported (in part) by the Intramural Research Program of the National Institutes of Health (NEH), National Institute of Environmental Health Science (NIEHS). We would like to thank Dr James C Bonner (North Carolina State University) for providing us with the MWCNTs used in this study. We would also like to thank Dr John Roberts and Robert Wine (NIH, NIEHS) for their assistance with the ECIS device, and Dr Jeff Tucker and Dr Agnes Janoshazi (NIH, NIEHS), for their assistance with obtaining the confocal images. We also thank Connie Cummings and Deloris Sutton (NIH, NIEHS) for their work with TEM.

\section{Disclosure}

The authors report no conflicts of interest in this work.

\section{References}

1. Nanotechproject.org. Project on Emerging Nanotechnologies; Updated 2013 October 28. Available from: http://www.nanotechproject.org/cpi/ about/analysis/. Accessed May 6, 2014.

2. Baughman RH, Zakhidov AA, de Heer WA. Carbon nanotubes - the route toward applications. Science. 2002;297(5582):787-792.

3. Bianco A, Kostarelos K, Prato M. Applications of carbon nanotubes in drug delivery. Curr Opin Chem Biol. 2005;9(6):674-679.

4. Kam NWS, O'Connell M, Wisdom JA, Dai HJ. Carbon nanotubes as multifunctional biological transporters and near-infrared agents for selective cancer cell destruction. Proc Natl Acad Sci U S A. 2005;102(33): 11600-11605.

5. Law M, Goldberger J, Yang PD. Semiconductor nanowires and nanotubes. Annu Rev Mater Res. 2004;34:83-122.
6. Donaldson K, Aitken R, Tran L, et al. Carbon nanotubes: a review of their properties in relation to pulmonary toxicology and workplace safety. Toxicol Sci. 2006;92(1):5-22.

7. Park EJ, Roh J, Kim SN, et al. A single intratracheal instillation of single-walled carbon nanotubes induced early lung fibrosis and subchronic tissue damage in mice. Arch Toxicol. 2011;85(9):1121-1131.

8. Shvedova AA, Kisin ER, Mercer R, et al. Unusual inflammatory and fibrogenic pulmonary responses to single-walled carbon nanotubes in mice. Am J Physiol Lung Cell Mol Physiol. 2005;289(5):L698-L708.

9. Lam CW, James JT, McCluskey R, Hunter RL. Pulmonary toxicity of single-wall carbon nanotubes in mice 7 and 90 days after intratracheal instillation. Toxicol Sci. 2004;77(1):126-134.

10. Ryman-Rasmussen JP, Tewksbury EW, Moss OR, Cesta MF, Wong BA, Bonner JC. Inhaled multiwalled carbon nanotubes potentiate airway fibrosis in murine allergic asthma. Am J Respir Cell Mol. 2009; 40(3):349-358.

11. Sharma CS, Sarkar S, Periyakaruppan A, et al. Single-walled carbon nanotubes induces oxidative stress in rat lung epithelial cells. J Nanosci Nanotechnol. 2007;7(7):2466-2472.

12. Tsukahara T, Haniu H. Cellular cytotoxic response induced by highly purified multi-wall carbon nanotube in human lung cells. Mol Cell Biochem. 2011;352(1-2):57-63.

13. Liu D, Wang LJ, Wang ZG, Cuschieri A. Different cellular response mechanisms contribute to the length-dependent cytotoxicity of multiwalled carbon nanotubes. Nanoscale Res Lett. 2012;7(1):361.

14. He XQ, Young SH, Schwegler-Berry D, Chisholm WP, Fernback JE, Ma Q. Multiwalled carbon nanotubes induce a fibrogenic response by stimulating reactive oxygen species production, activating NF-kappa B signaling, and promoting fibroblast-to-myofibroblast transformation. Chem Res Toxicol. 2011;24(12):2237-2248.

15. Xia T, Hamilton RF Jr, Bonner JC, et al. Interlaboratory evaluation of cytotoxicity and inflammatory responses to engineered nanomaterials: the NIEHS Nano Go Consortium. Environ Health Perspect. 2013; 121(6):683-690.

16. Haniu H, Saito N, Matsuda Y, et al. Elucidation mechanism of different biological responses to multi-walled carbon nanotubes using four cell lines. Int J Nanomedicine. 2011;6:3487-3497.

17. Wang X, Katwa P, Podila R, et al. Multi-walled carbon nanotube instillation impairs pulmonary function in C57BL/6 mice. Part Fibre Toxicol. 2011;8:24.

18. Godfrey RW. Human airway epithelial tight junctions. Microsc Res Tech. 1997;38(5):488-499.

19. Tiruppathi C, Malik AB, Del Vecchio PJ, Keese CR, Giaever I. Electrical method for detection of endothelial cell shape change in real time: assessment of endothelial barrier function. Proc Natl Acad Sci US A. 1992;89(17):7919-7923.

20. Bachmann M, Waldrop JE. Noncardiogenic pulmonary edema. Compendium. 2012;34(11):E1.

21. Wang G, Zhang J, Dewilde AH, et al. Understanding and correcting for carbon nanotube interferences with a commercial LDH cytotoxicity assay. Toxicology. 2012;299(2-3):99-111.

22. Murphy FA, Schinwald A, Poland CA, Donaldson K. The mechanism of pleural inflammation by long carbon nanotubes: interaction of long fibres with macrophages stimulates them to amplify pro-inflammatory responses in mesothelial cells. Part Fibre Toxicol. 2012;9:8.

23. Liu Y, Zhao Y, Sun B, Chen C. Understanding the toxicity of carbon nanotubes. Acc Chem Res. 2013;46(3):702-713.

24. Rotoli BM, Bussolati O, Barilli A, et al. Airway barrier dysfunction induced by exposure to carbon nanotubes in vitro: which role for fiber length? Hum Exp Toxicol. 2009;28(6-7):361-368.

25. Mani SA, Guo W, Liao MJ, et al. The epithelial-mesenchymal transition generates cells with properties of stem cells. Cell. 2008;133(4): 704-715.

26. Ke Y, Gerwin BI, Ruskie SE, Pfeifer AM, Harris CC, Lechner JF. Cell density governs the ability of human bronchial epithelial cells to recognize serum and transforming growth factor beta-1 as squamous differentiation-inducing agents. Am J Pathol. 1990;137(4):833-843. 
27. Lechner JF, Haugen A, McClendon IA, Pettis EW. Clonal growth of normal adult human bronchial epithelial cells in a serum-free medium. In Vitro. 1982;18(7):633-642.

28. Windoffer R, Beil M, Magin TM, Leube RE. Cytoskeleton in motion: the dynamics of keratin intermediate filaments in epithelia. J Cell Biol. 2011;194(5):669-678.

29. Dinu CZ, Bale SS, Zhu G, Dordick JS. Tubulin encapsulation of carbon nanotubes into functional hybrid assemblies. Small. 2009;5(3): $310-315$
30. Rodriguez-Fernandez L, Valiente R, Gonzalez J, Villegas JC, Fanarraga ML. Multiwalled carbon nanotubes display microtubule biomimetic properties in vivo, enhancing microtubule assembly and stabilization. ACS Nano. 2012;6(8):6614-6625.

31. Rawlins EL, Hogan BL. Epithelial stem cells of the lung: privileged few or opportunities for many? Development. 2006;133(13):2455-2465.

International Journal of Nanomedicine

\section{Publish your work in this journal}

The International Journal of Nanomedicine is an international, peerreviewed journal focusing on the application of nanotechnology in diagnostics, therapeutics, and drug delivery systems throughout the biomedical field. This journal is indexed on PubMed Central, MedLine, CAS, SciSearch ${ }^{\circledR}$, Current Contents ${ } /$ Clinical Medicine,

\section{Dovepress}

Journal Citation Reports/Science Edition, EMBase, Scopus and the Elsevier Bibliographic databases. The manuscript management system is completely online and includes a very quick and fair peer-review system, which is all easy to use. Visit http://www.dovepress.com/ testimonials.php to read real quotes from published authors.

Submit your manuscript here: http://www.dovepress.com/international-journal-of-nanomedicine-journal 